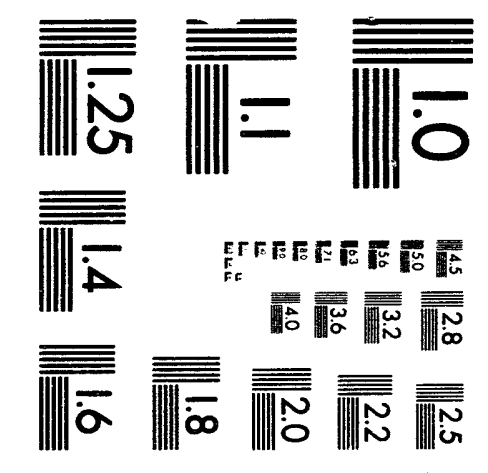



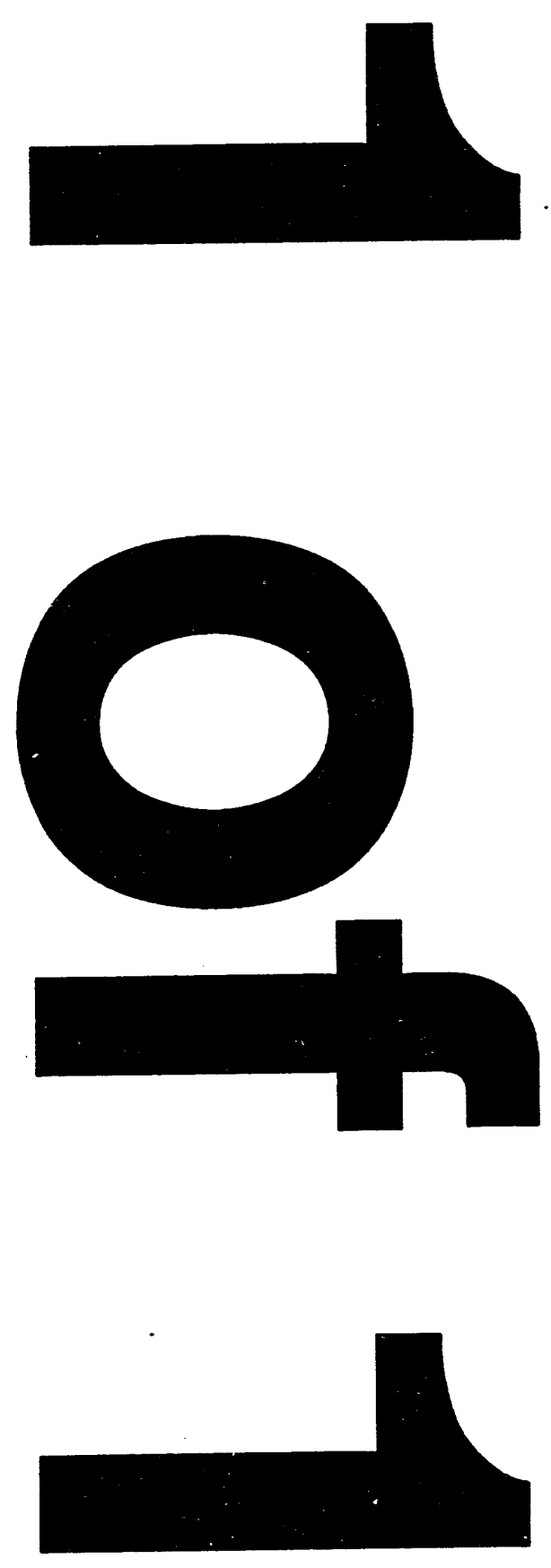
The aubmitted manuscript has been aunhorod by a contractor of the U.S. Government under contrect No. DE-AC05-84OR21400. Accordingly, the U.S. Govemment retains a nonexclusive, royaltyfree license to publith or reportuce the published farm of this contribution, a allow others to do so, for U.S. Govemment purposes."

\title{
Helium Transport and Exhaust Studies of H-mode Discharges in the DIII-D Tokamak*
}

\author{
D. L. Hillis, M. R. Wade, J. T. Hogan, W. P. West ${ }^{\dagger}$, K. H. Burrell ${ }^{\dagger}$, R. Maingi, \\ C. C. Klepper, M. M. Menon, P. K. Mioduszewski, M. A. Mahdavi ${ }^{\dagger}$, \\ G. L. Jackson ${ }^{\dagger}$, N. H. Brooks ${ }^{\dagger}$, D. F. Finkenthal ${ }^{\ddagger}$ \\ Oak Ridge National Laboratory, Oak Ridge, Tennessee USA \\ tGeneral Atomics, San Diego, Califomia USA \\ ҒUniversity of California, Berkeley, California USA
}

(Received

\begin{abstract}
A collaborative program has bee:s initiated to measure helium (He) transport and exhaust on DIII-D in L-mode, ELM-free H-mode, and ELMing H-mode. These diverted plasmas operating in enhanced confinement regimes should provide valuable information for the International Thermonuclear Experimental Reactor (ITER). To simulate the presence of $\mathrm{He}$ ash in DIII-D, a $50 \mathrm{~ms}$ He puff is injected into a DIII-D plasma, resulting in a $\mathrm{He}$ concentration of $\sim 15 \%$. The time dependence of the He density profiles in the plasma core is measured with charge-exchange recombination spectroscopy and the He spatial distribution on the divertor floor is studied with an impurity monitor array. The dependence of core transport diffusivities as a function of ELM frequency have been studied and the first demonstration made of $\mathrm{He}$ exhaust from an $\mathrm{H}$-mode plasma in a diverted tokamak. The exhaust rate of $\mathrm{He}$ from these ELMing $\mathrm{H}$-mode plasmas appears to be within the acceptable range for a fusion reactor, like ITER, based on a measured value of $\tau^{*} \mathrm{He} / \tau_{\mathrm{E}} \approx 14$.
\end{abstract}

\section{INTRODUCTION}

There would be substantial benefits in plasma performance if next-generation tokamaks, such as the International Thermonuclear Experimental Reactor (ITER), could be designed to operate in the enhanced confinement or $\mathrm{H}$-mode regime. One possible difficulty, however, is that the core plasma He particle confinement time is expected to be longer than that for L-mode (ITER Physics 1991). For burning fusion devices, continuous purging of the helium (He) ash is essential. Estimates (Reiter et al 1990) show that newly created $\mathrm{He}$ ions must be removed within 7 to 15 energy confinement times to maintain a continuous burn $\left(\tau^{*} \mathrm{He} / \tau_{\mathrm{E}} \leq 7-15\right)$. The ratio $\tau^{*} \mathrm{He} / \tau_{\mathrm{E}}$ is a global figure of merit for a reactor, where $\tau^{*} \mathrm{He}=\tau_{\mathrm{He}} /(1-\mathrm{R}), \mathrm{R}$ is the global He recycling coefficient, $\tau_{\mathrm{He}}$ is the helium particle confinement time, and $\tau_{\mathrm{E}}$ is the energy confinement time. Recent measurements (Hillis et al 1990, Hillis et al 1991, Synakowski et al 1990, Nakamura et al 1991, Sakasai et al 1993) on TEXTOR and other tokamaks have demonstrated that He can be readily transported from the plasma core in L-mode plasmas. The TEXTOR L-mode measurements (Hillis et al 1991) yielded values of $\tau^{*} \mathrm{He}^{/ \tau_{\mathrm{E}}} \approx 9-20$, which appear to $b t$ in the acceptable range for reactor ash control. More recent measurements on TEXTOR with ALT-II pumping (Hillis et al 1992) investigated an enhanced confinement regime (similar to an "ELM free" H-mode) which is produced by an edge polarization electrode (Weynants et al 1991). In the polarization-induced enhanced confinement regime the ratio $\tau^{*} \mathrm{He} / \tau_{\mathrm{E}}$ increases to about 70 , as compared with the L-mode value of $9-20$. These measurements suggest that He removal may be more difficult for high confinement regimes in burning plasmas; however, ELMing $\mathrm{H}$-mode conditions were not investigated in TEXTOR. A way to meet reactor ignition requirements could be realized if the helium

*Research sponsored by the Office of Fusion Energy, U.S. Department of Energy, under contract DE-AC05-840R21400 with Martin Marietta Energy Systems, Inc., and under contract DE-AC03-89ER51114 with General Atomics 
density in the core could be regulated by low-level edge-localized modes (ELMs) and sawtooth activity, without undue adverse effects on energy confinement. However, if He confinement in the core is too good in H-mode, even the most efficient particle removal scheme will not remove the He ash quickly enough.

Thus, a key task in H-mode physics is to determine and quantify the processes which govern the rate at which helium can be exhausted from ELMing H-mode plasmas. The successful execution of this task requires determination of the intrinsic transport properties of $\mathrm{He}$ in the core plasma under a wide range of conditions, the description of the influence of ELMs on the core transport rate, and the determination of the rate at which He can actually be exhausted from H-mode plasmas by pumping.

In this paper recent results from DIII-D experiments are presented which give an encouraging preliminary view of the suitability of the $\mathrm{H}$-mode for reactor plasmas in each of these aspects. The core transport rate has been studied as a function of ELM frequency (and/or neutral beam power), the role of ELMs in directly transporting $\mathrm{He}$ to the SOL has been observed, and the first demonstration of $\mathrm{He}$ exhaust from an $\mathrm{H}$ mode plasma in a diverted tokamak is presented.

\section{DIII-D EXPERIMENTAL SETUP AND METHOD}

To simulate the presence of He ash in DIII-D, concentrations of $15 \%$ He (relative to $\left.n_{e}\right)$ are puffed $(\sim 50 \mathrm{~ms})$ into the plasma during an otherwise steady-state phase of an $\mathrm{H}$-mode discharge. This gas is generally introduced approximately $300-400 \mathrm{~ms}$ after the L-H transition, providing enough time for the density and temperature profiles to come into equilibrium. For these experiments a lower, single-null divertor configuration was used with a toroidal magnetic field of $2.1 \mathrm{~T}$, and a major radius of $1.67 \mathrm{~m}$, and a plasma current Ip = 1.6 MA. The vacuum vessel walls were conditioned via boronization and periodic helium glow discharge cleaning (He GDC) between shots. Helium introduced into the vacuum vessel walls during $\mathrm{He} G D C$ results in an ambient helium level of approximately $\sim 3 \%$ (relative to $\mathrm{n}_{\mathrm{e}}$ ) during the plasma discharge. No He pumping is present for these discharges.

The transport of the He is monitored by measuring the temporal evolution of the helium density profile in the plasma core with a high resolution spectroscopy system, which uses the techniques of chargeexchange recombination (CER) spectroscopy in conjunction with neutral beam (NB) injection. The DIII-D CER system consists of 32 viewing chords, which span the entire plasma cross section (Gohil et al 1992). Helium density profiles are derived from measurements of the intensities of the He II $(n=4 \rightarrow 3)$ transition at $4686 \AA$. Absolute calibration of the sensitivity of each chord has been accomplished using standard calibration lamps and injection of the neutral beam into a gas-filled torus.

\subsection{DIII-D experiments in $H$-mode without helium pumping}

A typical ELM-free H-mode discharge on DIII-D is shown in figure 1 along with the $D_{\alpha}$ and He signals (measured by a photomultiplier array which views the divertor floor at the strike point of the divertor flux). To induce the $\mathrm{H}$-mode, $10.4 \mathrm{MW}$ of neutral beam power is injected for $200 \mathrm{~ms}$. To maintain an ELM-free $\mathrm{H}$-mode, the beam power is then reduced to $4.4 \mathrm{MW}$ for the remainder of the discharge. For the ELM free discharge of figure 1, an ELM free $\mathrm{H}$-mode period of about $0.5 \mathrm{~s}$ is achieved. Just after the $50 \mathrm{~ms}$ He puff at $2.0 \mathrm{~s}$, the line averaged electron density increases and both the He and $D_{\alpha}$ photomultiplier signals increase dramatically. From 2.1 to $2.5 \mathrm{~s}$ in figure 1, an ELM free H-mode is maintained, before the appearance of 6 giant ELMs. During the ELM-free period the electron density continues to rise until $2.5 \mathrm{~s}$ when the first giant ELM appears; a slight drop in the density occurs with each of the subsequent giant ELMs.

In figure 2 the He density profile for the ELM-free period $(t=2.36 \mathrm{~s})$ is plotted versus the normalized radius, $\rho$, and compared to the electron density profile measured via Thomson scattering. During this ELMfree period, both profiles have similar flat central profiles and steep edge gradients. The shape of the electron density profile and the He density profile are essentially the same. During this ELM free period the energy confinement time $\tau_{E}$ is about $200 \mathrm{~ms}$. To investigate the influence of ELMs on the He density profile, the He 
profile is displayed in figure 3 for the period of time just before $(t=2.66 \mathrm{~s})$ and during the giant ELM at $2.68 \mathrm{~s}$. The He density profile indicates that $i$ Ie is lost from the edge plasma $(\rho>0.5)$ during the giant ELM, while the profile is unaffected for $\rho<0.5$. The He photodiode signals of figure 1 shows that the $\mathrm{He}^{+}$line emission from the divertor increases abruptly when $\mathrm{He}$ is purged from the core plasma edge, suggesting a sharp increase in the
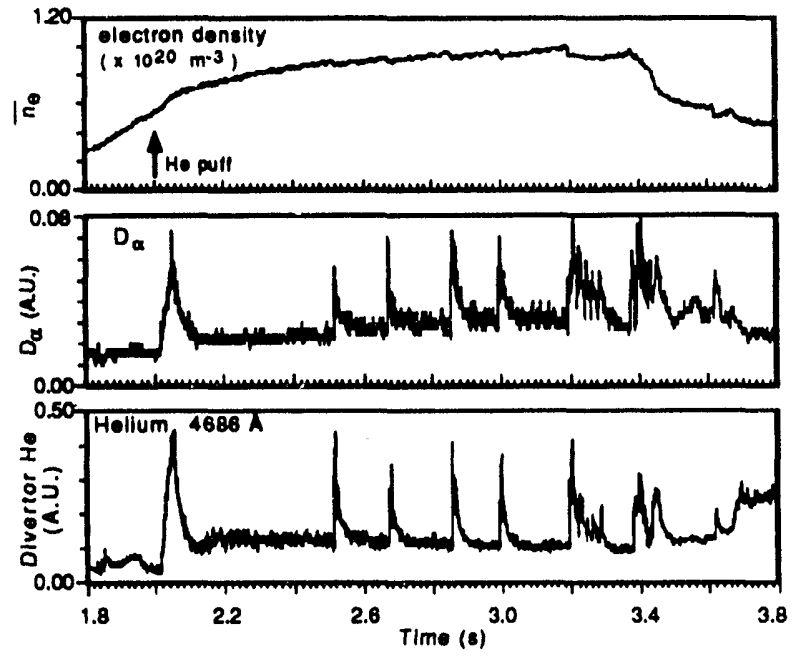

Figure 1. An $\mathrm{H}$-mode discharge with an ELM-free period of $500 \mathrm{~ms}(2.0-2.5 \mathrm{~s})$ followed by a series of giant ELMs. Displayed are $n_{e}$ and the divertor $D_{\alpha}$ and $\mathrm{He}(4686 \AA)$ signals, measured with photomultipliers that view the region near the divertor strike point.

divertor He content. If pumping were provided in the baffle region of DIII-D, then the $\mathrm{He}$ purged during the ELM event could be removed.

In figure 4 , a comparison of the $\mathrm{He}$ density profiles is presented for a typical L-mode and a typical $\mathrm{H}$-mode discharge on DIII-D. The $\mathrm{H}$-mode discharge shown in figure $4 \mathrm{~b}$ has an ELM frequency of $\approx 40 \mathrm{~Hz}$. Unlike the ELM-free $\mathrm{H}$-mode, He density profile which has a very steep edge gradient, the L-mode and ELMing $\mathrm{H}$-mode discharge $\mathrm{He}$ density profiles fall off more slowly near $\rho=1$. The data of figure 4 have been modeled with the MIST impurity transport code (Hulse et al 1983), which has been modified to include the DIII-D non-circular geometry. MIST uses as input the experimentally measured $n_{e}$ and $T_{e}$ (Thomson scattering) profiles as a function of radius and time, and ELM effects are found to be well represented by the parametrization of the Helium flux in terms of a pinch term based on $n_{e}$. The helium particle flux $\Gamma_{\alpha}$ is described by an anomalous diffusivity, $D_{H e}$, and a pinch coefficient, $C_{v}$, where the pinch velocity, $\mathrm{V}_{\alpha}$, is defined by:

$$
n_{e} V_{\alpha}(r)=C_{v} D_{H_{e}}(r) \frac{\partial n_{e}}{\partial r}
$$

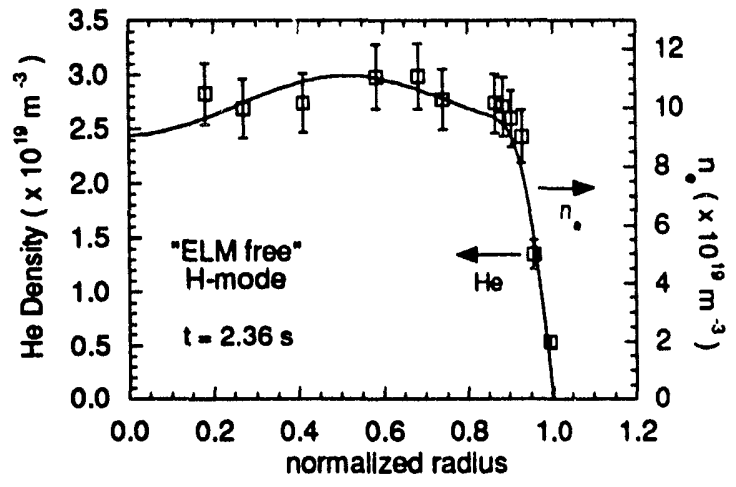

Figure 2. Typical electron and He density profile for the ELM-free period shown in figure 1. The points with error bars are CER measurements of the He density, and the solid line is $\downarrow$ spline fit through the Thomson scattering measurement of the electron density.

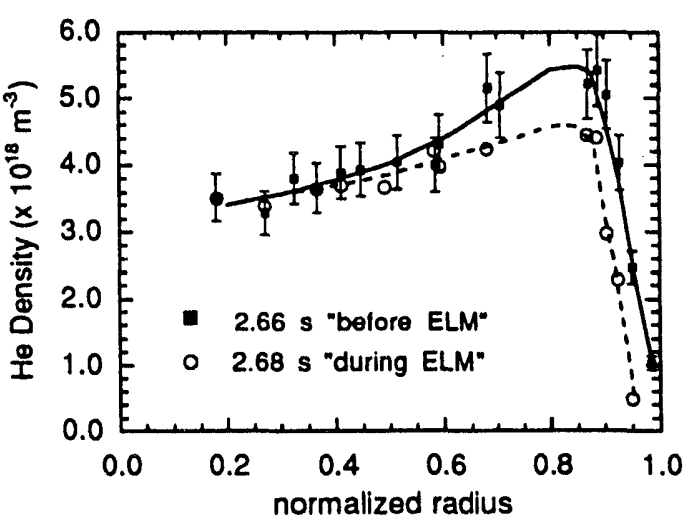

Figure 3. Helium density profile measured with CER spectroscopy just before and after a giant ELM event during the $\mathrm{H}$-mode discharge of figure 1. 
In an equilibrium state, the pinch coefficient has the form $C_{v}=L n_{e} / L n_{\alpha}$ where $L n_{e}$ and $L n_{\alpha}$ are the electron and helium density gradient scale lengths, respectively. Hence, if the helium and electron density profiles have the same shape, $\mathrm{C}_{\mathrm{v}}=1.0$, indicating no preferential accumulation or dilution of helium in the discharge.

The code requires as input a spatially dependent anomalous diffusivity, $D_{\mathrm{He}}$ (core) $\sim 0.1 \mathrm{~m}^{2} / \mathrm{s}$ to $D_{\mathrm{He}}$ (edge) $=0.9 \mathrm{~m}^{2} / \mathrm{s}$, a pinch coefficient $\mathrm{C}_{\mathrm{v}}$, and a global recycling coefficient $\mathrm{R}_{\mathrm{He}}$, which is 1 for these cases without He pumping. The value of $D_{H e}$ and $C_{v}$ is then determined by finding the best comparison between the simulation and the measured profiles through iterative runs of the MIST code. The MIST results are shown in figure 4 as solid or dashed lines for comparison with the He data points. The transport coefficients needed to match the He profile evolution of the ELMing H-mode case are $D_{\mathrm{He}} \approx 0.9 \mathrm{~m}^{2} / \mathrm{s}$ and $\mathrm{C}_{\mathrm{v}} \approx 1.0$. For the discharges studied thus far on DIII-D (L-mode, ELM-free H-mode, and ELMing H-mode),
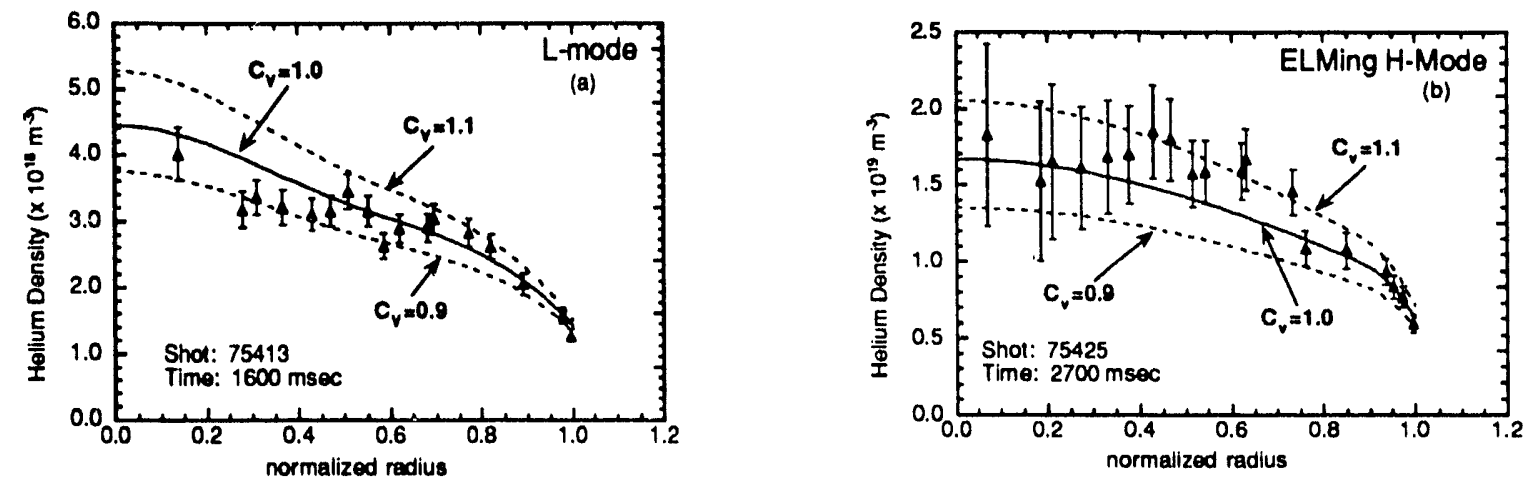

Figure 4. Helium density profiles measured during L-mode and ELMing $\mathrm{H}$-mode at Ip $=1.6 \mathrm{MA}$ along with curves showing the sensitivity to variation of the pinch coefficient $C_{v}$. The curve corresponding to $C_{v}=1.0$ is the normalized electron density profile derived from Thomson scattering measurements.

the pinch coefficient $\mathrm{C}_{\mathrm{v}}$ is very close to unity, thus suggesting that enrichment of helium in the core of a fusion reactor may not be a significant problem.

\subsection{Effects of ELMs on helium transport}

Several experiments have shown that impurity accumulation is not as prevalent in ELMing H-mode discharges with ELMs (Luxon 1991). As is demonstrated in figure 3, the ELMs purge a significant amount of He from the plasma edge (for $p>0.5$ ). ELMs also have an effect on global energy and particle confinement. Previous studies on DIII-D have shown that ELMs only slightly modify the global energy confinement time from similar quiescent $\mathrm{H}$-mode discharges $(\approx 20 \%)$ (Schissel et al 1992). Since the ELMs are quite effective in removing helium from the edge of the plasma, it is conceivable that by controlling the ELM frequency, one may be able to lower $\tau^{*}{ }_{\mathrm{He}} / \tau_{\mathrm{E}}$ without compromising a great deal on energy confinement (or, alternatively, $\mathrm{D}_{\mathrm{He}} / \chi_{\text {eff }}$, where $\chi_{\mathrm{eff}}$ is the thermal conductivity). To experimentally determine the value of $\tau^{*}{ }_{\mathrm{He}}$ requires active He exhaust, which was not available for our core transport measurements; therefore, the quantity $\mathrm{D}_{\mathrm{He}} \chi \chi_{\text {eff }}$ is determined for the steady state phase of the discharge as was done for recent TFTR transport experiments (Synakowski et al 1993).

To investigate the influence of ELM frequency on He transport in DIII-D, the ELM frequency was varied during successive discharges by changing the neutral beam injection power while the plasma current was held fixed at 1.6 MA. In this manner, the ELM frequency was varied from $0 \mathrm{~Hz}\left(\mathrm{P}_{\mathrm{NBI}}=4.0 \mathrm{MW}\right.$ ) to $120 \mathrm{~Hz}$ $\left(\mathrm{P}_{\mathrm{NBI}}=12.5 \mathrm{MW}\right.$ ). During this scan, the global energy confinement time decreases by a factor of 3 (due to an increase in injected power), while MIST analysis indicates an almost eight-fold increase in $\mathrm{D}_{\mathrm{He}}$. The quantity $D_{\mathrm{He}} \chi_{\text {eff }}$ for these ELMing H-mode discharges is plotted versus the ELM frequency in figure 5 . Here $\chi_{\text {eff }}$ is determined from the DIII-D - ONETWO transport code using the experimental profiles from Thomson 
scattering, electron cyclotron emission, $T_{i}, Z_{e f f}$, and radiated power. The value of $D_{H e} / \chi_{e f f}$ increases from a value of $\sim 0.4$ for an ELM free $\mathrm{H}$-mode $(0 \mathrm{~Hz})$ to $\sim 1.3$ for an ELM frequency of $120 \mathrm{~Hz}$. This suggests that a favorable trend exists for enhancing helium transport relative to energy transport as the ELM frequency is increased and makes an ITER scenario based on ELMing H-mode conditions more feasible.

\subsection{DIII-D experiments in H-mode with active He pumping}

Recently, the first active He pumping experiments were performed on DIII-D using the advanced divertor program (ADP) cryo-pump (reference), which was conditioned with an Ar frost layer to provide He pumping (Kim et al 1990). During the active He pumping phase of the experiment the ADP cryo-pump was conditioned with an Ar frost layer of $\sim 1500$ torr-liters of Ar between shots, which provides a He pumping speed of about 12,000 liters/s. Figure 6 shows two identical DIII-D discharges: one without active He pumping (no conditioning of the cryo-pump with Ar frost), and a second discharge with active He pumping. These discharges were similar to the discharges described earlier, but the plasma current was 1.0 MA. For these discharges in figure 5, feedback control on the external $\mathrm{D}$ gas fueling was used to keep the electron density of the background plasma approximately constant, $\mathrm{n}_{\mathrm{e}} \approx 4 \times 10^{19} \mathrm{~m}^{-3}$ during the NB phase. In figure 5 the He density rises sharply just after the He gas puff $(t=1.5 \mathrm{~s})$, and the He appears in the core plasma $(\rho=0.3)$ within $100-200 \mathrm{~ms}$. For both of the discharges the outer strike point is well removed from the pumping baffle until $2.0 \mathrm{~s}$, when the outer strike point is moved into the optimum pumping location near the ADP pump (major radius, $R=1.71 \mathrm{~m}$ ). For the case without pumping, the He density remains constant after the initial rise, indicating full recycling $\left(\mathrm{R}_{\mathrm{He}} \approx 1.0\right)$ of the He. With active He pumping, which begins at $2.0 \mathrm{~s}$, the He density drops rapidly and $\sim 70 \%$ of the He found in the discharge is exhausted within $\sim 2 \mathrm{~s}$. This discharge is an ELMing H-mode discharge with an ELM frequency of $\sim 40 \mathrm{~Hz}$. The active removal of $\mathrm{He}$ from this ELMing H-mode discharge is very similar to the results found on TEXTOR for an L-mode discharge (Hillis et al 1990). Utilizing the decay of the He density versus time during the pumping phase, the He particle confinement time, $\tau^{*} \mathrm{He}$ in the vacuum vessel is $\tau^{*} \mathrm{He} \approx 2.5 \mathrm{~s}$. Diamagnetic measurements provide estimates of the energy confinement time, $\tau_{\mathrm{E}} \approx 0.180 \mathrm{~s}$. For the ELMing H-mode discharge of figure 5 , this yields a $\tau^{*} \mathrm{He}^{/ \tau} \approx 14$, which is in the acceptable range for a fusion reactor. This data is for an ELM frequency of only $40 \mathrm{~Hz}$ and, based upon the data of figure 4, as one goes to higher ELM frequencies ("grassy" like ELMs), one can expect an even more optimistic value for $\tau^{*} \mathrm{He}^{/ \tau_{\mathrm{E}}}$.

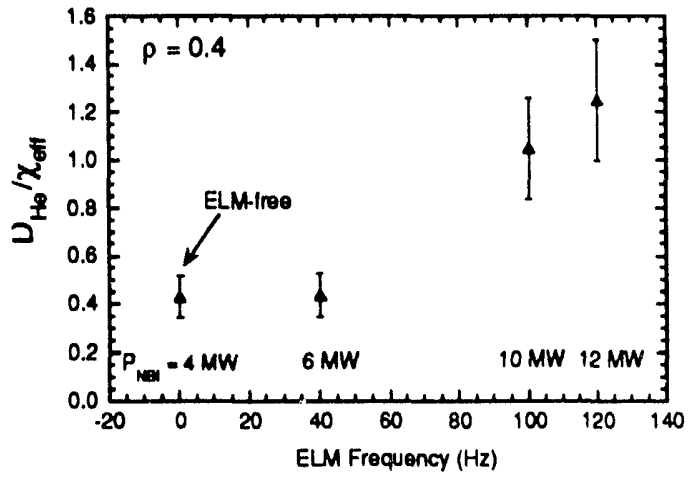

Figure 5. Scaling of the parameter $D_{H e} x_{\text {eff }}$ as the ELM frequency is varied from $0 \mathrm{~Hz}$ (ELM-free) to $120 \mathrm{~Hz}$. The ELM frequency is varied by increasing the input neutral beam power, which is indicated above the ELM frequency.

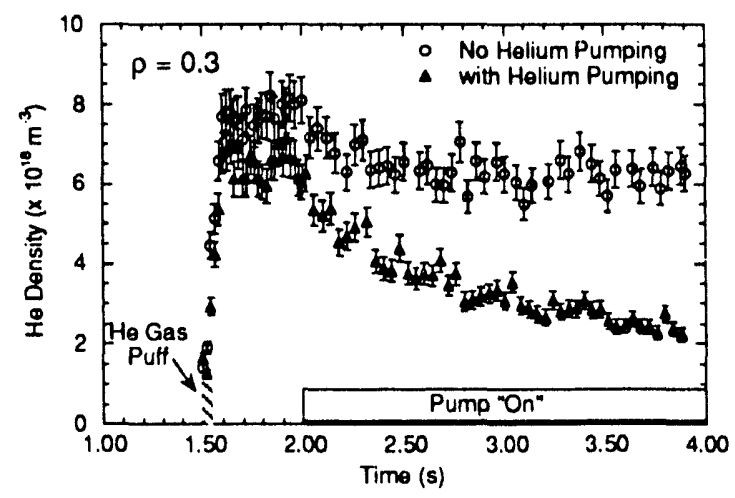

Figure 6. He density $(\rho=0.3)$ measured with CER spectroscopy versus time both with and without $\mathrm{He}$ pumping on DIII-D after a short $50 \mathrm{~ms}$ He puff at $1.5 \mathrm{~s}$. 


\section{SUMMARY AND CONCLUSIONS}

In these DIII-D experiments, a first look at the effects of ELMs on H-mode He transport has been presented. During a giant ELM event, the He is purged from the plasma edge for $\rho>0.5$; it is observed in the divertor as evidenced by an increase in a He photodiode measurements in the divertor chamber. It is also observed that as ELM frequency is increased the ratio of the He particle diffusivity and the heat conductivity, $D_{H e} / \chi_{\text {eff }}$ also increase. This is strong evidence that higher ELM frequencies will expel He more efficiently from the discharge into the divertor where it can be removed by an active exhaust system. Finally, these experiments have shown that He can be exhausted efficiently from an $\mathrm{H}$-mode plasma in a diverted tokamak with a value of $\tau^{*} \mathrm{He} \tau_{\mathrm{E}} \approx 14$, which appears to be within the acceptable range for a fusion reactor, like ITER. Future experiments on DIII-D will investigate this ratio over a larger operational space and for higher ELM frequencies, as well as employ He neutral beam injection to provide a ceniral source of $\mathrm{He}$.

\section{Acknowledgments}

We are indebted to the DIII-D operations and diagnostics groups for their assistance in performing these experiments. We wish to thank Dr. M. von Hellermann of the JET Joint Undertaking for his many helpful discussions and for the JET atomic physics database which was used in obtaining the absolute He density profiles.

\section{References}

Gohil P, Burrell K H, Groebner R J et al 1992 14th Symp. on Fusion Engineering (New York: IEEE) vol 2 p 1189

Hillis D L, Finken K H, Hogan J T et al 1990 Phys. Rev. Lett. 652382

Hillis D L, Hogan J T, Horton L D et al 1991 Proc. 13th Int. Conf. on Plasma Physics and Controlled Nuclear Fusion Research, Washington, DC (International Atomic Energy Agency, Vienna) vol 3 p 597

Hillis D L, Hogan J T, Finken K H et al 1992 J. Nucl. Mater. 196-198 35

Hulse R A 1983 Nucl. Technol./Fusion 3259

ITER Physics 1991, ITER Documentation Series no 21 (International Atomic Energy Agency, Vienna)

Kim J, Schaubel K M, and Colleraine A P 1990 J. Vac. Sci. Technol. A8

Luxon J L 1991 Plasma Physics \& Controlled Fusion

Nakamura H, Hirayama T, Koide Y et al 1991 Phys. Rev. Lett. 672658

Reiter D, Wolf G H, Kever H 1990 Nucl. Fusion 302141

Sakasai A, Koide Y, Nakamura H et al 1993 Proc. 1993 Int. Conf. on Plasma Physics (Lisbon: European Physical Society) vol 1 p 67

Schissel D P, DeBoo J C, Burrell K H et al 1991 Nucl. Fusion 3173

Schissel D P, Osborne T H, Carlstrom T N et al 1992 Proc. 1992 Int. Conf. on Plasma Physics (Innsbruck: European Physical Society) vol 16C part 1 p 235

Synakowski E, Efthimion P C, Rewoldt G et al 1990 Phys. Fluids B5 2215

Weynants R R, Bora D, Delvigne T et al 1990 Proc. 13th Int. Conf. on Plasma Physics and Controlled Nuclear Fusion Research, Washington, DC (International Atomic Energy Agency, Vienna 1991) vol 1 p 473

\section{DISCLAIMER}

This report was prepared as an account of work sponsored by an agency of the United States Government. Neither the United States Government nor any agency thereof, nor any of their employees, makes any warranty, express or implied, or assumes any legal liability or responsibility for the accuracy, completeness, or usefulness of any information, apparatus, product, or process disclosed, or represents that its use would not infringe privately owned rights. Reference herein to any specific commercial product, process, or service by trade name, trademark, manufacturer, or otherwise does not necessarily constitute or imply its endorsement, recommendation, or favoring by the United States Government or any agency thereof. The views and opinions of authors expressed herein do not necessarily state or reflect those of the United States Government or any agency thereof. 

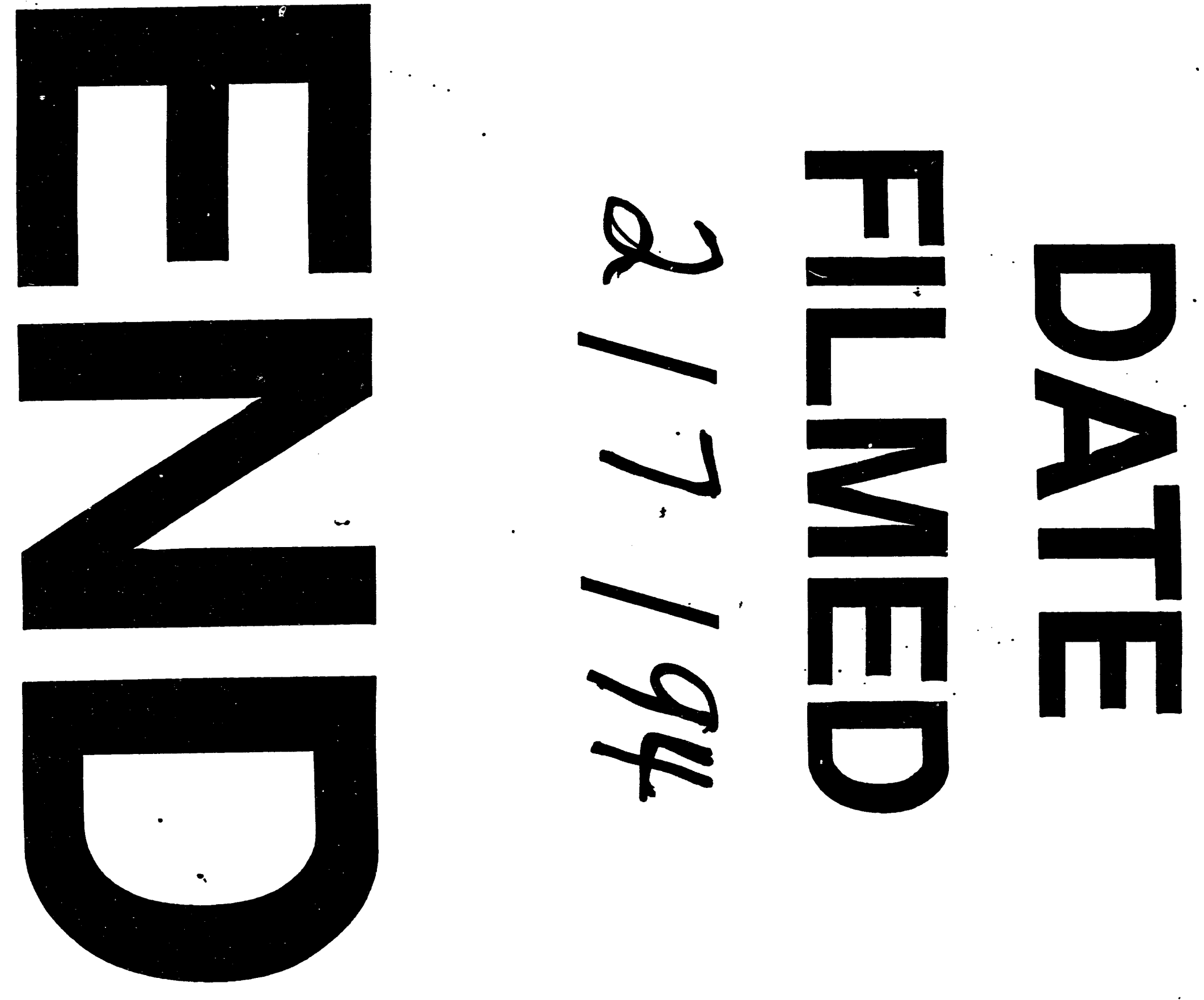


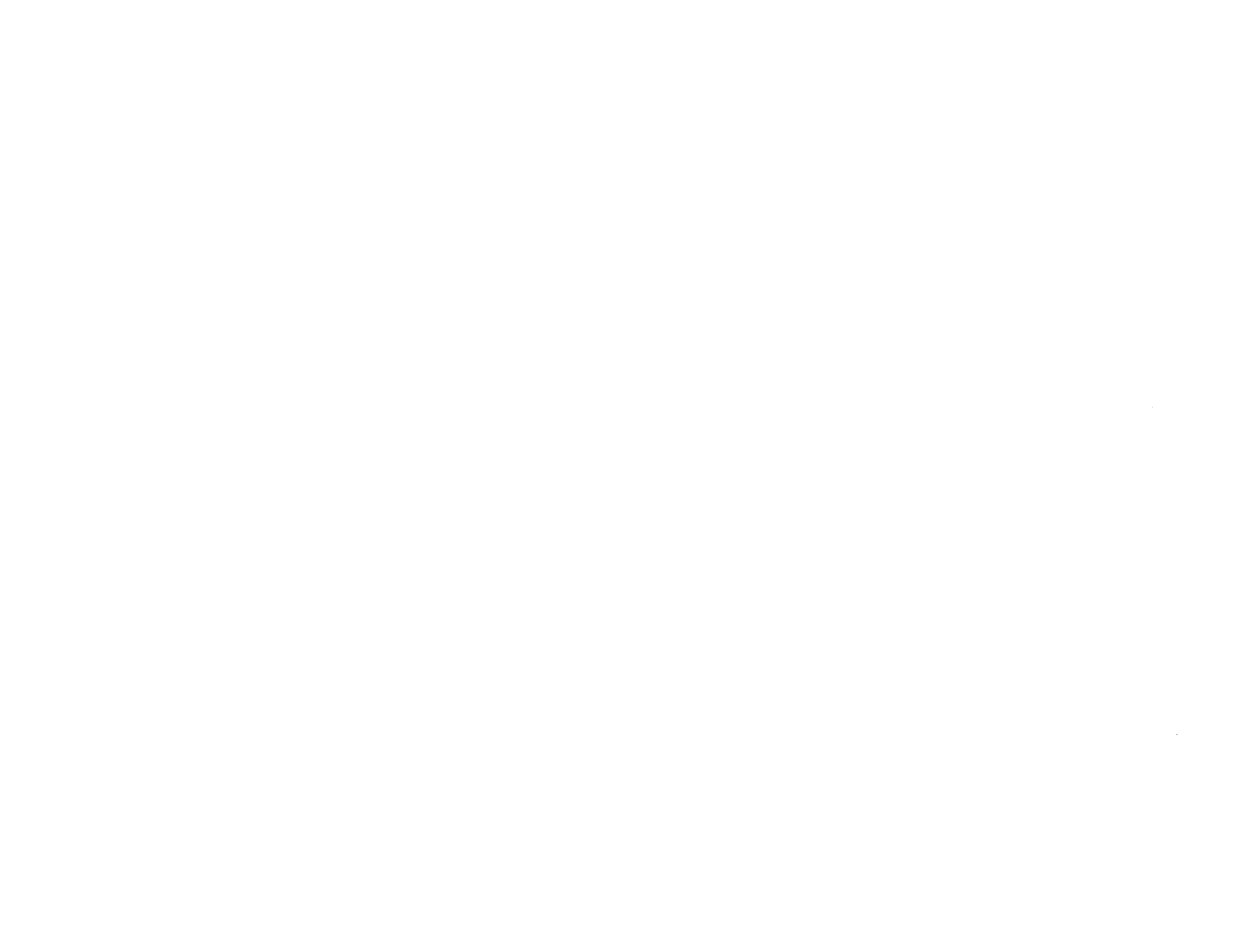

